\title{
Food Safety Labelling Management in the Green Supply Chain Management: A Direct Observational Study in the Vietnamese Retail Food Sector
}

Author(s): Eunsung Kim, Scott McDonald

Source: Journal of International Logistics and Trade 2018; 16(3):95-108

Published by: Jungseok Research Institute of International Logistics and Trade, Inha University

DOI: https://doi.org/10.24006/jilt.2018.16.3.095

The Journal of International Logistics and Trade is an official journal published by Jungseok Research Institute of International Logistics and Trade, Inha University, Korea. JILT welcomes manuscripts that advance the practice and science of logistics, trade, and other related fields.

Frequency: Quarterly (March, June, September, December)

Stable URL: https://www.ejilt.org

The Jungseok Research Institute of International Logistics and Trade is a specialized academic research institute representing Inha University and the Inha Foundation in Korea. The institute aims to become a representative institute in Northeast Asia in the research of logistics and trade.

Stable URL: https://jrieng.inha.ac.kr

(C) Copyright. Jungseok Research Institute of International Logistics and Trade.

This is an Open-Access article distributed under the terms of the Creative Commons Attribution NonCommercial License (http://creativecommons.org/licenses/by-nc/4.0/) which permits unrestricted noncommercial use, distribution, and reproduction in any medium, provided the original work is properly cited 


\title{
Journal of
}

\section{Food Safety Labelling Management in the Green Supply Chain Management: A Direct Observational Study in the Vietnamese Retail Food Sector}

\author{
Eunsung Kim ${ }^{\mathrm{a} *}$, Scott McDonald ${ }^{\mathrm{b}}$ \\ a School of Graduate Research, RMIT University, Australia \\ ${ }^{\mathrm{b}}$ Department of Logistics \& Supply Chain Management, School of Business \& Management, RMIT University, Vietnam
}

\section{ARTICLE INFO}

Article history:

Received 10 October 2018

Accepted 15 December 2018

Keywords:

Consumer food safety standard Vietnamese good agricultural practices (VietGAP) Logo

\begin{abstract}
Maintaining food safety techniques in the supply chain management require special food safety labelling techniques during distribution in the retail food industry. The food products have to be of good quality and labelling inbound, manufacturing, and outbound in the supply chain contributes to this aim. The purpose of this study is to evaluate how food safety labelling is managed in Vietnam's retail food industry with a special focus on food in Ho Chi Minh City, Vietnam. Photography was used in an observational study conducted among five separate retail market chains all located in this city. In which ways are the applications of the developed food safety labelling techniques among three separate retail food markets similar and dissimilar being accounted for? The results show that the packaging and labelling in Big C, Aeon Citimart, and Giant using the symbols of food safety build trust for their customers. The Big C indicates guidelines for VietGAP and green labelling. Aeon Citimart indicates the name of the good, expiration date and instructions for use as well as guidelines for the government factor (VietGAP) to the food safety practices in the Vietnamese food retail sector.
\end{abstract}

\section{Introduction}

Vietnam's retail market is characterized as being one of the most dynamic markets in the region with high annual growth rates. The retail sales of organic food products estimated the current market capacity at US\$153.5 million a year since organic food products have become popular in Vietnam (Vietnamnet, 2018). According to the Australian Government, (2018), the Vietnamese food retail sector is expanding fast. For example, the number of retail food markets in Vietnam was around 750 supermarkets, 130 shopping centers and 9,000 traditional markets in 2016. Furthermore, foreign investment in the retail food sector such as Big C, Aeon Citimart and Giant is developing the change in consumption patterns from the traditional market to the foreign supermarket. In the aspect of government food safety standard policies, the Government explicitly aims to reduce food safety incidents through a combination of legislation and retail modernization. In the aspect of government food safety policies, the Ministry of Agriculture and Rural Development (2008) posted the Vietnamese Good Agricultural Practices (VietGAP) which is a standards and guidelines for production of fresh fruit and vegetables aimed at preventing or minimizing the risk of hazards which occur including food safety, produce quality, environmental impacts, health, safety and welfare for Vietnamese workers (Ministry of Agriculture and Rural Development, 2008). The Government explicitly aims to reduce food safety incidents through a combination of legislation and retail modernization. Legislation in Vietnam (Law on Food Safety (LoFS), No.55/QH12/2010) aims to assure that 'food shall not cause any harm to people's health and lives' (Wertheim-Heck, Vellema, and Spaargaren 2015). The government policies also serve to assist individuals or organizations, producers and

\footnotetext{
* Corresponding author: School of Graduate Research, RMIT University Australia, 124 La Trobe St, Melbourne VIC 3000, Australia; Email: casio947@gmail.com
} 
consumers to prevent risks of food safety, harvesting, and post-harvest handling of fresh fruit and vegetables.

Table 1 indicates the five separate retail company profiles in Vietnam. Vietnam's retail food market has welcomed many big retailers in the world such as Aeon, Big C, and Giant the leading retailer to invest in large supermarkets in Vietnam (Pham, 2017; Deloitte, 2014). Foreign direct investors Retail Corporation has been trying to implement their standard ways in collaboration with new environmental rules and certification requirements in green manufacturing (Pham, 2017; Khoi, Dung and Nga, 2016).

Table 1. Company profiles

Source: Smith and Vo (2016)

\begin{tabular}{|c|c|c|c|}
\hline $\begin{array}{l}\text { Retailers name } \\
\text { Outlet type }\end{array}$ & Ownership & Locations & Purchasing agent type \\
\hline $\begin{array}{l}\text { Aeon: Citimart } \\
\text { Supermarkets }\end{array}$ & $\begin{array}{l}\text { Share-holding company } \\
\text { Japan and Dong Hung (VN) }\end{array}$ & \multirow{3}{*}{ Ho Chi Minh City } & $\begin{array}{l}\text { Mainly from local producers, importers and } \\
\text { distributors }\end{array}$ \\
\hline $\begin{array}{l}\text { Big C: } \\
\text { Hypermarkets and } \\
\text { Supermarkets }\end{array}$ & $\begin{array}{l}100 \% \text { owned by Group } \\
\text { Thailand }\end{array}$ & & $\begin{array}{l}\text { Dry foods and beverages mainly from local } \\
\text { producers, importers, distributors and wholesalers }\end{array}$ \\
\hline $\begin{array}{l}\text { Giant: } \\
\text { Supermarkets }\end{array}$ & $\begin{array}{l}\text { Foreign invest company by } \\
\text { Singapore }\end{array}$ & & $\begin{array}{l}\text { Mainly from local producers, importers and } \\
\text { distributors }\end{array}$ \\
\hline
\end{tabular}

In recent years, growing awareness of environmental concerns in combination with health concerns about food risk management on food safety has led consumers to question good agricultural practices for organic food. This has been reflected in an increasing demand for organic food production, which is perceived as less damaging to the environment and to be healthier than conventionally grown foods (Janssen and Hamm, 2014; Stolz et al., 2011).

In addition, the potential negative effects of dietary pesticide residues on human health have been related to an increasing human health risk (Mie et al., 2017). Some diseases such as Parkinson's disease, cancers, and childhood leukemia or lymphomas are reported as a reason linked to the exposure from dietary pesticide residue (Curl et al., 2015; Ye et al., 2015; Ntzani et al., 2013; Moisan et al., 2015; Thuy et al., 2012; Maele-Fabry, Hoet and Lison, 2013; Young et al., 2005; Chen, 2015).

\section{Literature review}

\subsection{Vietnamese good agricultural practices (VietGAP)}

According to Long, 2014, the organic agriculture sector has been emerging since the late 1990s starting with some specific products, such as spices and essential edible oils, meant for exporting to European countries and the USA. While most organic agricultural industries have undergone important transformations over the past couple of years, the areas of production including organic teas, vegetables, rice, spices, honey, and aquatic animals had been experiencing substantial growth. The statistical information in 2015 revealed that Vietnam had 76,666 hectares for organic agricultural land, of which were only $0.7 \%$ of the total agricultural land of Vietnam (Helga Willer, 2017; World Bank, 2016).

As a result, aspects of Vietnam's agricultural success have come at the expense of the environment, for example, in 2007, the Vietnamese Ministry of Health reported 4,670 poisoning cases caused by pesticides, of which 248 were food poisoning cases resulting in 101 deaths (Thuy et al., 2012). The VietGAP is mainly for local markets to monitor organic farming. Thus, a national basic standard for organic production was established by the Ministry of Agriculture and Rural Development in 2007 (Long, 2014).

In Vietnam, food safety and agricultural health action plans are generally prescriptive with the aim being to reach the desired levels of domestic food safety and increased international market access (World Bank 2006). However, pesticide control laws have not been implemented because of limited environmental standards, a lack of incentive for making regulators enforce the law, and insufficient knowledge (Phung et al., 2012). The Ministry of Agriculture and Rural Development posted the Vietnamese Good Agricultural Practices (VietGAP) which is a standards with guidelines for the production of fresh fruit and vegetables and is aimed at preventing or minimizing the risk of hazards which occur including food safety, produce quality, environmental impacts and health, as well as the safety and welfare for Vietnamese workers (Thi and Giang, 2015; World Bank Group 2016b; The World Bank 2016). They also serve to assist individuals or organizations, producers and consumers to prevent risks to food safety, harvesting, and post-harvest handling of fresh fruit and vegetables.

Furthermore, factor that determining consumer buying intention have been brought to light marketing research, however, the information of cultural influencing, market and customer related factors still is far away for marketer and retailers engaging in the organic food retail sector. In Vietnam, there is a variety of supermarket doing business in the retail food sector. Some of the retailers and marketers are focusing on different groups of socio-demographic variables.

In the retail food sector, the consumer goes shopping to buy food products somewhere. So the information for the 
retailers and marketers are that customer expectation regarding organic food products move upward and this study attempts to fill the gap by examining the relationships between food safety standards and retailers' food safety labelling performance in leading organic food consumption in the Vietnamese Retail Food Sector.

However, pesticide legislation and regulations have not been developed in response to this large increase in usage, as a result of which pesticides pose a serious threat to human health and the environment (Phung et al., 2012). Some of the international standards that safeguard food safety (e.g. Global GAP, ISO 22000:2005, ISO 22005:2007), have gained a wide acceptance in several countries during recent years in order to achieve maximum safety (Cartín-Rojas, 2013).

Limited research has explored the ways investigating the relationship between consumer related forces and consumer behavior in food retail industry (Sakthirama and Venkatram, 2013; Radder and le Roux, 2005). However, the implementation of Consumer Food Choice Model and the impact of food choice motives are still in a nascent stage (Sakthirama and Venkatram, 2013) in South East Asia market. With increasing environmental concerns, the Vietnamese government has become interested in developing a policy on good agricultural practices for the production of fresh fruit and vegetables in terms of food safety risk management.

However, there are few studies on consumer behavior towards organic food in the Vietnamese retail food industry. The purpose of this study will investigate the underlying motives driving consumers' food choices and to identify and explain the factors that influences consumer buying intention of organic food in the Vietnamese retail food industry.

\subsection{Green agriculture products supply chain (GAPSC)}

Zhao et al. (2013) define Green Agriculture Products Supply Chain (GAPSC) as "the concept of green, health and environmental protection throughout the agriculture products supply chain in the product life cycle process". The GAPSC for the organic agriculture sector can be divided into green purchasing, green production, green manufacturing, green logistics, green marketing, green consumption, and advocate green consumption, to ensure the quality and safety of agricultural products. GAPSC is a series of production systems that maintain the environmental sustainability, using organic pesticides and avoiding, for instance, the use of antibiotics and growth hormones. The organic producer might respect established norms in all production stages, from the seeding process until packaging, always concerned with the process' impact on the natural environment (Marques Vieira et al., 2013). Most of the literature has focused on standard regulations for potential hazardous foods or GAPSC performance measurement. The model of GAPSC in organic products is presented (as shown in Figure 1).

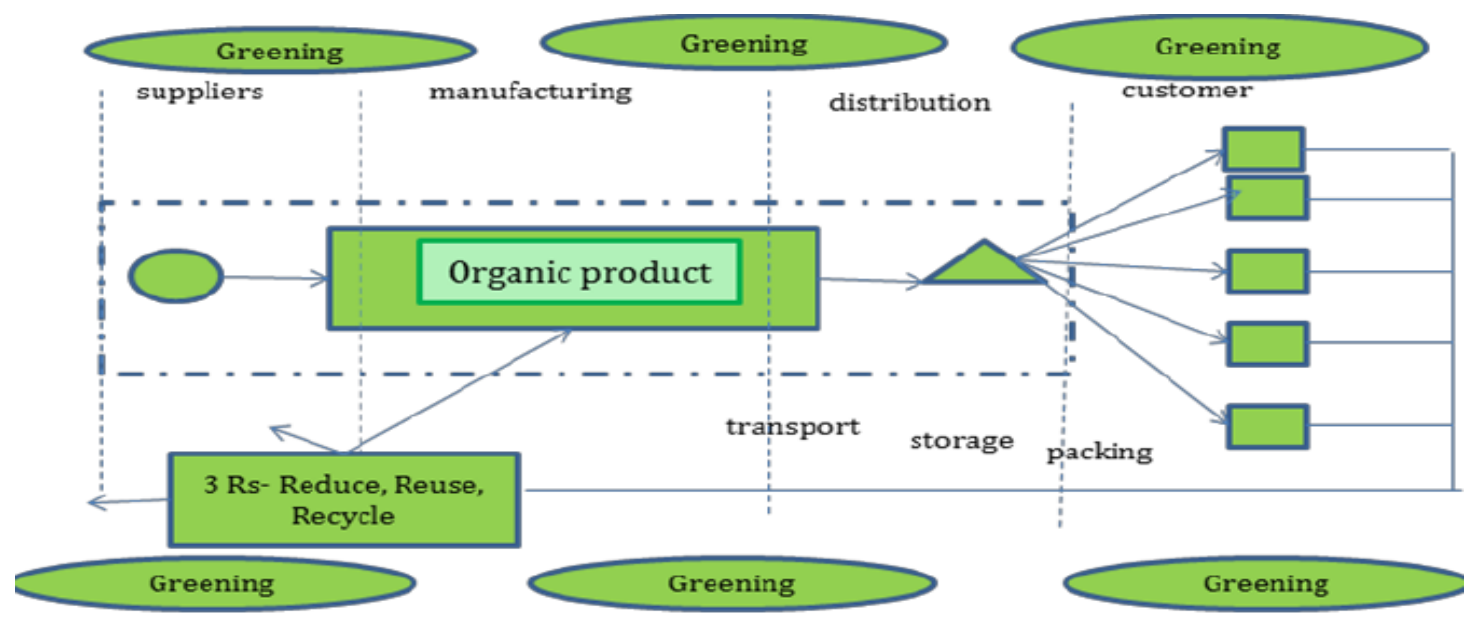

Figure 1. Model-based green supply chain of green short supply chain in organic products (adapted from Tundys and Rzeczcki (2014))

From the above Figure 1, it is evident that an organic agricultural sector has as many short supply chains as it has farming, manufacturing and retailers, because for each organic product, the shopper's requirements and the conventional tactics of purchasing might be different. In addition, one of the goals of the short supply chains' management is to "promote the organization of the food supply chain and the management of the risks of the agricultural sector, with particular attention towards: a better integration of the primary producers in the food supply chain in accordance with quality assurance schemes" (De Fazio, 2016). In addition, organic production and transportation will be eco-friendly, with distribution systems constructed in the most optimal design for reducing the environmental costs of packaging.

\subsection{Elements of labelling design}


Food and Pharmaceutical Products such as labelling, and packaging are integrated elements of products safety standards. Product design is a broad term that included a considerable range of designs elements. Bloch (1996) indicated elements of packaging design are an integral part of the brand name (Bloch, 1995). This design also decides how to integrate two embodiment elements in terms of food safety technology and food safety information. Kim and McDonald food safety labelling model suggests the effective collaboration between the guideline of the government policy sector and the private sector in implementing the legal framework to ensure access to the retail food industry (Kim and McDonald 2018). Furthermore, Kim and McDonald food safety labelling model has classified the good safety labelling management into three broad categories which are labelling, environmental labelling standards, and national legislation (Fig. 2).

The concept of Kim and McDonald food safety labelling techniques involves the regulation of inputs such as labelling and barcode, national legislation, HACCP and ISO, which implements logical conjunction. If all seven inputs of correct labelling contribute to the gate of food safety management, self-designed brands and Eco Symbols by retailers can be shown to have high output results in food safety labelling management. KIM and McDonald food safety labelling techniques improve food safety labelling and environmental standards by using an observational study for improving the visualization of food safety labelling management and contributing an environmental solution in the following ways (Kim and McDonald 2018).

Despite, the growing emphasis on Food and Pharmaceutical products insecurity in developing and under developing countries, however, The Kim and McDonald model cannot insight the complex technology in terms of packaging and labelling. Kim and McDonald food safety labelling model has classified the good safety labelling management into three broad categories which are labelling, environmental labelling standards, and national legislation (Figure 2). First, the labelling category composed of four subcategories such as names of products, expiration dates, and instructions for use, and barcodes. Second, a food safety system comprised of ISO (Quality Management System) and HACCP (Hazards and Critical Standards) certified food products, such as the description of the food safety system, hazards and Critical Standards, and environmental labelling standards. Third, national legislation comprised of Good Agricultural Practices, for instance, the management of pesticides and quality control management.

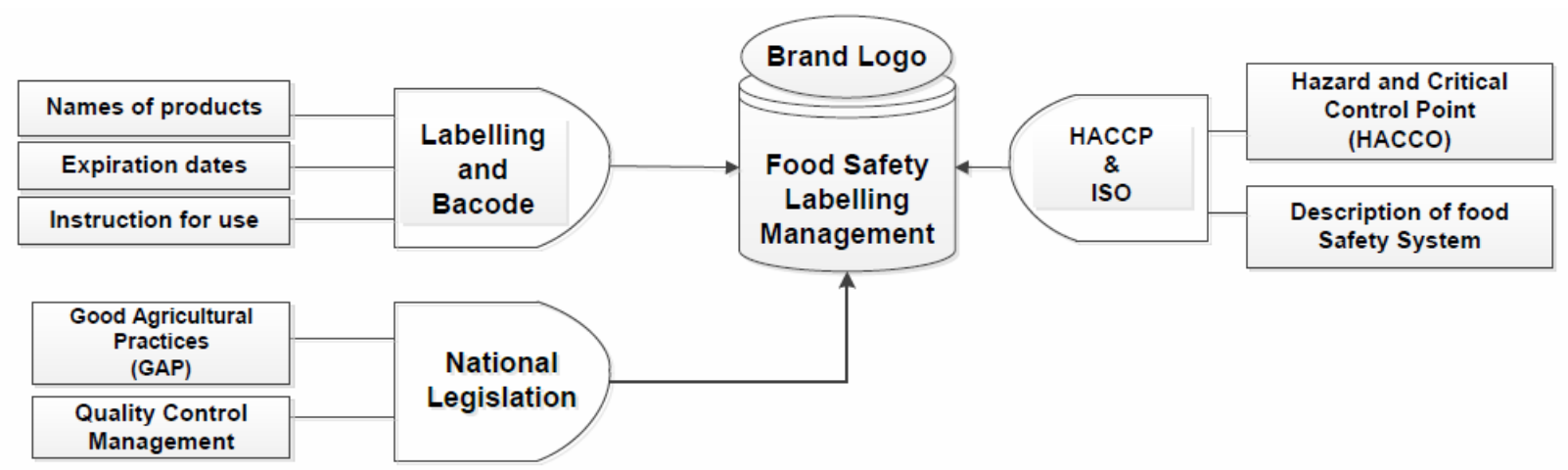

Figure 2. Design of Kim and McDonald food safety labelling techniques. Source: Kim and McDonald 2018)

The design of Kim and McDonald food safety labelling techniques involves the regulation of inputs such as labelling and barcode, national legislation, HACCP and ISO, which implements logical conjunction. If all seven inputs of correct labelling contribute to the gate of food safety management, self-designed brands and Eco Symbols by retailers can be shown to have high output results in food safety labelling management. Kim and McDonald food safety labelling techniques improve food safety labelling and environmental standards by using an observational study for improving the visualization of food safety labelling management and contributing an environmental solution.

\subsection{Food safety standard practices}

Food Safety Standard practices refer to the integration of environmental management and risk controls thinking into retail sector with entire process including planning, procurement, production, consumption as a Food Safety Standard Management (adapted from Sulistio and Rini, 2015). Food Safety Standard practices have been previously examined in the operations management and environmental management literature; (Junior et al., 2015; Mohanty and Prakash, 2014). Even with above research, the findings of the factor analysis have established for professionals in Food Safety Standard practices that it is becoming increasingly important to be green by applying the greening principles to all factors of the Food Safety Standard practices such as material sourcing, selection, manufacturing and reaching the customer with green products (Mohanty and Prakash 2014; Srivastava, 2007).

However, there is some literature that concludes that integration of specific frameworks in place to choose a supplier in terms of environmental practices (Howard and Elting 2013). Their findings are in the economic performance and environmental performance of packaging waste, economic transport, and product recycling as a green capability. Thus, 
their findings did not come from testing for the hypothesis which considered the integration of Food Safety Standard practices (Howard and Elting, 2013). Furthermore, their findings did not come from testing the hypothesis which considered the connection between integration of management systems and firm performance, so their finding was interesting but lacks a theoretical foundation. León-Bravo et al., (2017) suggested that a set of four different food safety standard practices stages such as breeding, processing, distribution, and retail as the key actors in terms of product quality and food safety management in food supply chain management. The findings indicate that each stage selects the different collaboration schemes for environmental sustainability practices' implementation with upstream actors and results show the diverse sustainability objectives pursed along the value supply chain.

As mentioned above, using supply chain integration alone may not improve all dimensions of sustainable firm performance. Thus, in order to enhance environmental and economic outcomes, it is necessary to consider food safety standard practices as a mediator with supply chain integration (Chiu and Hsieh 2016). Sulistio and Rini, (2015) argued that green food is a big believer in business association to improve sustainable performance and that establishing supplier in the supply chain values positive note as a sustainable firm's performance. Thus, in order to enhance green purchase intention, it is necessary to consider food safety standard practices such as an environmental, food safety, and product quality integration in business association to improve sustainability. According to existing food safety standard practices research, there are a number of measures of sustainable of forms performance. For example, companies should cooperate with environmentally sustainability performance in the manufacturing industry including product design, eco-labelling with green packaging, cleaner production, green products, and transportation (Suansawat 2013). Companies should provide consumers with clear information on environmentally friendly products. For this research, food safety standard practices categorized into three variables such as food safety standards and product distinctiveness and food safety labelling management as internal forces and environmental consideration as an external force in order to examine the retailers" food safety labelling management performance.

\section{Problem statement}

Most recently the World Bank (2017) reports that the use by farmers of antibiotics in animal feeds is the norm and in addition was using as many as 15 veterinary drugs in the feed. The guidelines of organic agriculture not only restrict use of chemical fertilizers, but it is also not permitted to use pesticides to use in certified organic agriculture. The requirements for safe vegetable production are not nearly as stringent (Simmons, 2008). The USA and EU had authorized its own United States Department of Agriculture (USDA) and Council Regulation (EC) No 834/2007 to control conventional pesticide ingredients or ionizing radiation (Tundys, 2015). Despite Vietnam being the largest agricultural producer in South East Asia, there are few studies related to food safety labelling management in the Vietnamese retail food industry. Furthermore, the most recently available retail market data is not comprehensive enough to describe the organic market in the Vietnamese retail food sector. Furthermore, there are still a few on green packaging management practices in Vietnam's retail food sector. In addition, there are few studies addressing the combination of government guidelines, labelling, and logos on food safety labelling management in the retail food sector.

The aim of this research is to identify the lack of consumer awareness and trust and it suggests a model that increases the effectiveness of eco-labels and the accuracy in understanding the meanings. Research objectives are to identify the main category of Kim and McDonald food safety labelling techniques regarding agricultural products among three separate retail markets; and to measure insights, the guideline, green labelling, and brand logos of Kim and McDonald food safety labelling techniques in the retail food markets. Drawing on data from an observational study of five food retail markets in Ho Chi Minh City, this study aims to address the following types of research questions:

- How does the Vietnamese Government implement the food safety guideline in the food safety labelling management in Vietnamese retail food industry?

- In which ways are the applications of the developed food safety labelling techniques among five separate retail food markets similar and dissimilar being accounted for?

\section{Methodology}

Gadd and Karstedt (2012) states that essentially, observations involve "Ethnography observation, using photography in qualitative research requires a theory of how pictures get used by both picture makers and viewers". One researcher observed the three different retail markets from November to December 2017. The observer took up the recorded images and documentation during observation periods as a methodological tool. The observations focused on how the retailer is constructing a design of the company logo and guidelines of labelling in order to make food safety labelling manageable and functional. Photography was used in an observational study conducted among five separate retail market chains all located in Ho Chi Minh City, Vietnam. The study focused on identifying which fresh vegetables, fruits, and meat categories were labelled and thus used as cases in this study. 


\subsection{Analyses on green labelling principles among three retail markets}

Green labelling is a standard that addresses dealing with environmental sustainability (Boström and Klintman, 2008). For instance, the symbolically distinguished label is based on standardization which beneficially represents the effects on consumer buying behavior in terms of environmental, health and food quality (Boström and Klintman, 2008). In Vietnam, food labelling is designed to give the consumer a sense of satisfaction for the safety and quality of the food that they buy is produced within a regulation of food processing, for example, Vietnamese Government's Decree No. 43/2017/ND-CP dated April 14, 2017 (International Trade Centre, 2012).

The four mandatory contents of goods labels in the regulation of green packaging management are the name of the goods, expiration date, safety warning, and instructions for use. The mandatory contents of the label of goods include (Dries, 2017) as follows:

- Name of the goods: For mandatory information as prescribed, the color of letters, numbers, picture, and symbol on label must be in contrast with the background color of the goods label (Dries, 2017)

- Expiration date: Date of manufacture and expiration date must be written in the "day-month-year" format, and must also be noted in this order if those dates are presented in another order on the product (Dries, 2017)

- Safety warning (if any)

- Instructions for use

The study was conducted to identify the company logos and food safety labelling management without implementing equation into the Vietnamese retail food sector in terms of government policy and guidelines influences on application and implementation to the private retail food sector in the direct observational qualitative method. That is, the study was conducted to investigate the national legislation implemented into the food safety labelling performance among three retailers (Aeon Citimart, Big C, and Giant); to investigate the brand logos of food safety labelling performance among three retailers (Aeon Citimart, Big C, and Giant); and to investigate how the name of goods, expiration date would implement on food safety labelling performance among three retailers (Aeon Citimart, Big C, and Giant).

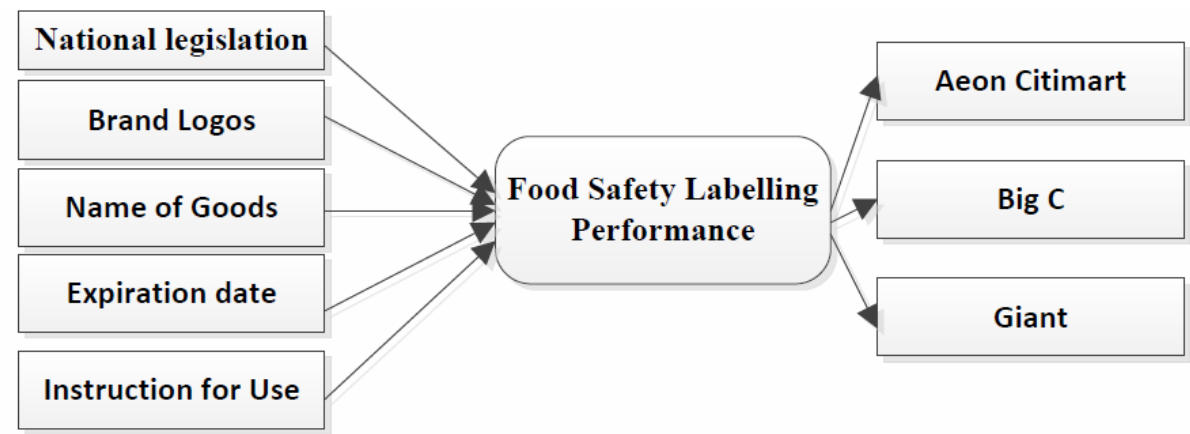

Figure 3. Conceptual model to investigate food safety labelling performance

\subsection{Samples}

First, a pre-observation was carried out among three retails markets at Aeon Citimart, Big C, and Giant in Ho Chi Minh City, Vietnam in order to identify which fresh vegetables and fruits categories were to be labelled as cases. The three types of food products such as fruit, vegetables, and meat were presented and displayed as interesting from a food retail market perspective. After identifying which categories would be included in the study, the observations were conducted as three separate observations on-site during a period between 27th of November 2017 and 31 st of December 2017. The 9 photographs were selected to illustrate the Vietnamese government policy of VietGAP, labelling and the design of retailer's own brand logo after purchasing the products among three retail markets.

\subsection{Data analysis}

The researcher conducted primary data collection from the three retail food markets in Ho Chi Minh City. First, the organizing pictures sources stored under the internal folder to organize the picture sources in Navigation View (NVivo 11 pro). Second, the illustration outputs were used with the image editor software (Adobe Photoshop CS 6) to identify food safety labelling and implementation to private logos in the Vietnamese retail food sector. The results were analyzed by illustrating the government policy of VietGAP and the retailer's own logo. The outcome variable in the analysis, labelling of fresh fruit and vegetables was illustrated. Types of guidelines, labelling, and logo were represented by using photography based on visual ethnography. 


\section{Results}

\subsection{Green labelling: government regulation level}

Food packaging must satisfy the requirements for food safety and product quality from contamination during their preservation and must facilitate labelling (Bendeković, Naletina and Nola, 2015; WTO, 2017). Government regulation of food law plays the guiding role of the green packaging management such as packaging, storage and transportation containers used for organic products that do not contaminate the organic product through the regulation and food law (International Trade Centre, 2012; Auler, Teixeira and Nardi, 2017; IFOAM, 2012).

Table 2 indicates the logo of VietGAP in Vietnamese food satisfaction policy. The VietGAP contains standards and guidelines to prevent risks of food safety and food quality. The VietGPA is certified by government policy along with criteria which adopted food safety and good quality in Vietnam's retail sector (Thai and Pensupar, 2015). Table 2 indicates an illustration of the label of VietGAP among three retail markets in Ho Chi Minh City, of which insight is to be applied to the standard of VietGAP in the private retail sector. The VietGPA standardization is certified by government policy and private organizations along with criteria which adopted organic standards and good quality in Vietnam's retail food sector.

Table 2. Illustration of attributes and attribute labels (VietGAP)

Source: Self-elaboration on basis of observation of retail markets in Ho Chi Minh City.

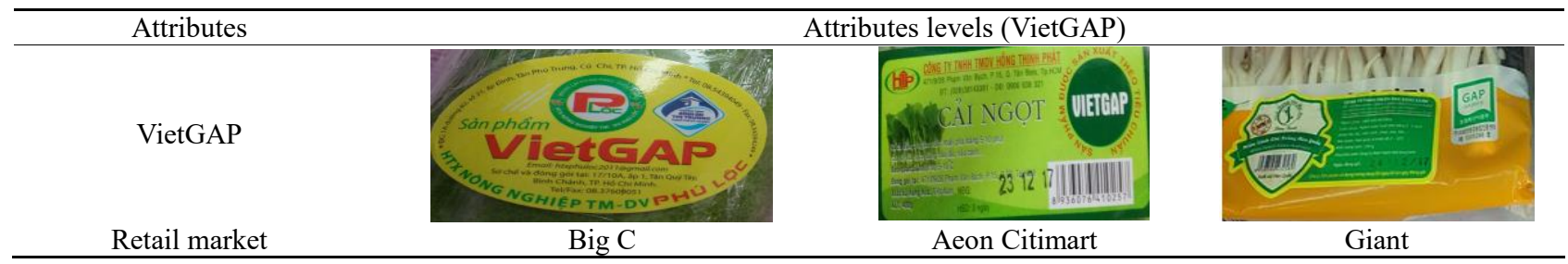

\subsection{Functions of green packaging}

Green packaging design needs to consider the structure of the reasonable packaging material (Zhou, 2014; Marsh and Bugusu, 2007). Especially, plastics packaging has several advantages such as being inexpensive and lightweight, and easy to print (Zhou 2014). The food retail sector, through the green packaging management to reduce the use of packaging materials and easy recycling packaging materials, can be improved by using green food safety design (Gao and Zhang, 2012; Alves and Edwards, 2008). According to Marsh and Bugusu, (2007), the function of food packaging management provides food protection in a cost-effective way that satisfies food supply requirement and consumer desires, maintains food safety, and minimizes environmental impacts.

Table 3. Illustration of packaging and labelling (Attributes and attribute levels) Source: Self-elaboration on basis of observation of retail markets in Ho Chi Minh City.

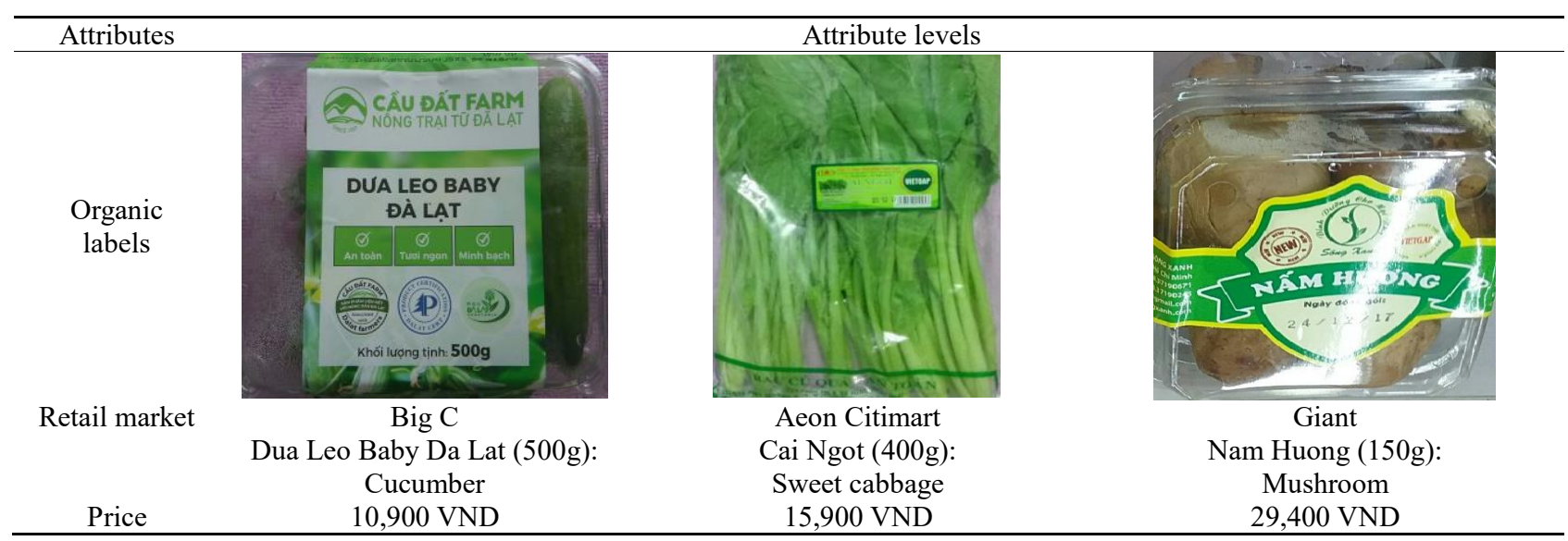

Johansson (2002) and Huang (2013) define eco-design as the actions taken during the product development stage targeted towards minimizing a product's environmental impact during its product life-cycle starting from acquiring raw materials for manufacturing, the use of the product and finally the disposal of the product without compromising other essential product criteria such as performance and cost. Lakshmmimeera and Palanisamy (2013) investigated the 
conceptual framework on related eco-design practices and packaging related eco-design practices on environmental, economic and intangible performances and found that eco-design practices are to create an environmental stance as a driver for improved brand image. Table 3 indicates an illustration of the green labelling among three retail markets in Ho Chi Minh City, Vietnam of which insight to be applied to the standard of VietGAP in the private retail food markets. The VietGPA standardization is certified by government policy and private organization along with criteria which adopted organic standards and good quality in Vietnam's retail food sector.

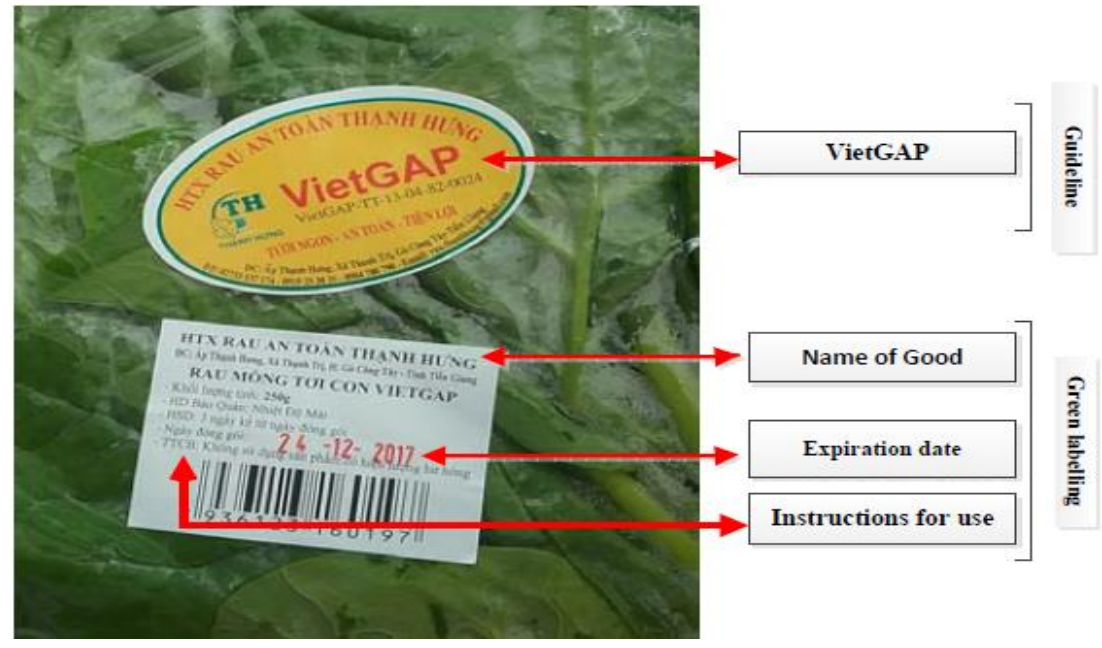

Figure 4. Attribution of guideline and labelling. Source: Self-elaboration on basis of observation of Big C Mart in District 7

\subsection{Green packaging management has a positive impact on the success of the food retail sector}

The organization of Food Safety Standards System in Vietnam is controlled by the Ministry of Science and Technology (MOST) and is coordinated by the Ministry of Health (MOH), Ministry of Trade (MOT), Ministry of Agriculture and Rural Development (MARD), Ministry of Fisheries (MOFI), Ministry of Industry (MOI), Ministry of Finance (MOF), and Ministry of Culture and Information (MCI) (Keirin Association, 2006). The Ministry of Agriculture and Rural Development (2008) posted VietGAP which contains standards and guidelines to assist individuals or organizations, producers and consumers to prevent risks to food safety, produce quality and workers in production, as well as harvesting and postharvest handling of fresh fruit and vegetables. These also serve to protect the environment and are used for product identification, traceability and recall.

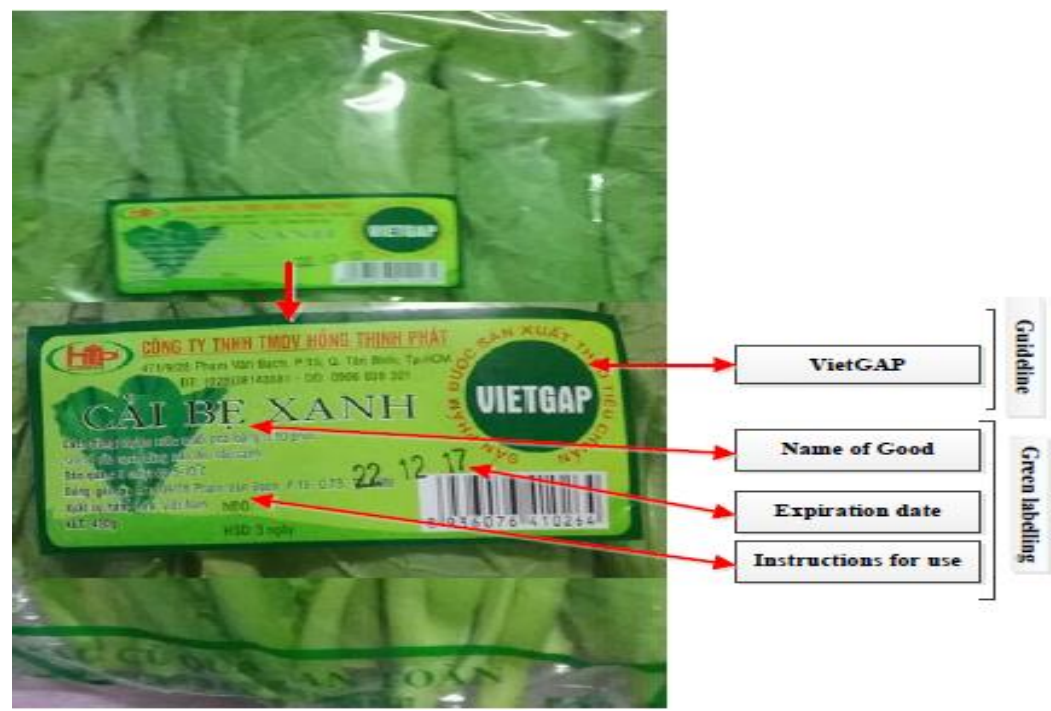

Figure 5. Attribution of guideline and labelling. Source: Self-elaboration on basis of observation of Aeon Citimart in District 7

The results show that the packaging and labelling in Big $\mathrm{C}$ using the symbols of food safety builds trust for their customers. Figure 4 indicates the contents of green packing and labelling in Big $\mathrm{C}$ such as guidelines or government 
factors and guidelines of VietGAP and green labelling (name of goods, expiration date, and instructions for use) in order to ensure food safety for the customers significantly impact the success of applying the government guidelines to the food safety practices in the Vietnamese food retail sector.

Figure 5 shows the label contents of Aeon Citimart indicates (name of good, expiration date, instructions for use) and guidelines of government factor (VietGAP) to the food safety practices in the Vietnamese food retail sector. The results show that the packaging and labelling in Big $\mathrm{C}$ using the symbols of food safety builds trust for their customers. Furthermore, figure 5 indicates the contents of green packing and labelling in Aeon Citimart such as guidelines or government factors and guidelines of VietGAP and green labelling (name of goods, expiration date, and instructions for use) in order to ensure food safety for the customers significantly impact the success of applying the government guidelines to the food safety practices in the Vietnamese food retail sector.

Figure 6 shows the label contents of Giant indicates (name of good, expiration date, instructions for use) and guidelines of government factor (VietGAP) to the food safety practices in the Vietnamese food retail sector. Furthermore, figure 6 indicates the contents of green packing and labelling in Giant such as guidelines or government factors and guidelines of VietGAP and green labelling (name of goods, expiration date, and instructions for use) in order to ensure food safety for the customers significantly impact the success of applying the government guidelines to the food safety practices in the Vietnamese food retail sector. However, the results show that the packaging and labelling in Giant not using the brand logo of food safety builds trust for their customers.

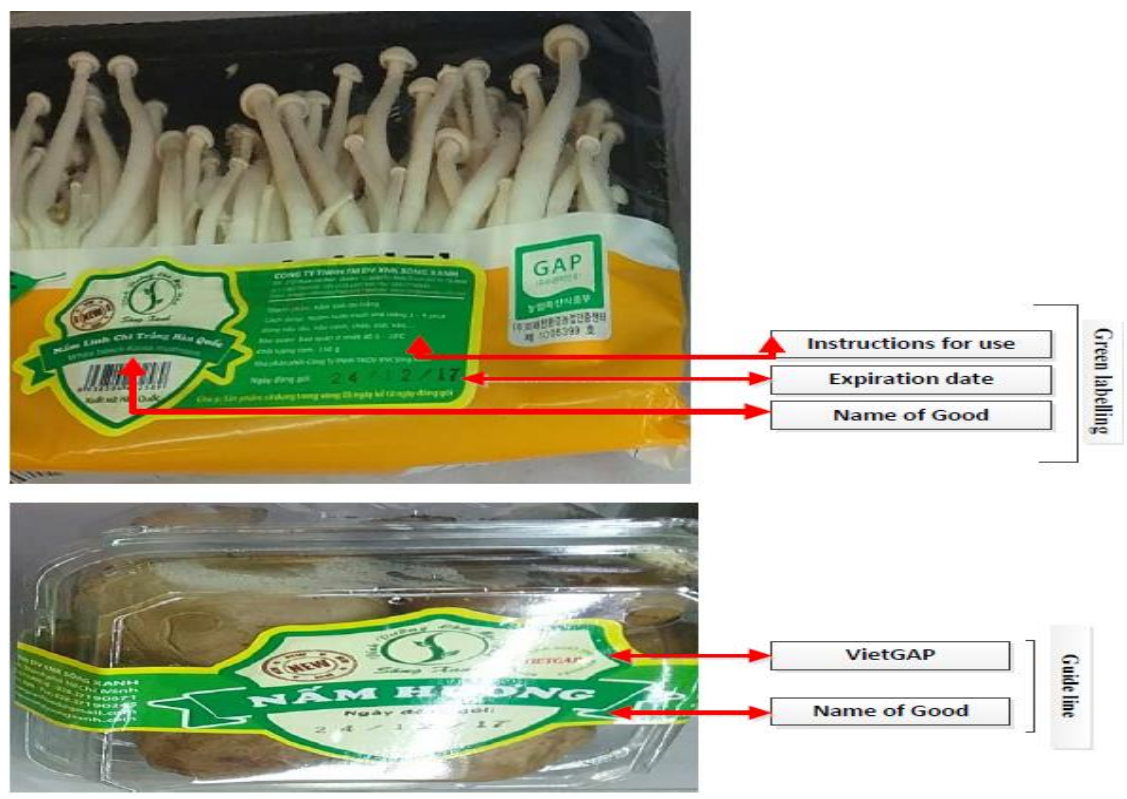

Figure 6. Attribution of labelling and guidelines. Source: self-elaboration on basis of observation of Giant in District 7

\section{Discussion}

The food safety labelling management performance of three retailers posited that national legislation, ISO \& HACCP standard, brand logo of private retailers in food safety standard practices positively effect on food safety labelling management performance of three retailers. The food safety standard practices implementation factors to be confirmed in our study include environmental consideration, food safety, and product distinctiveness, national legislation, ISO \& HACCP, and brand logo of private retailers.

Green packaging management in the retail industry has become increasingly important for several actors in its role as a value-adding element for the success of a product on the consumer market (Olsson, Lindh, and Bertoluci, 2011). In addition, green purchasing can be defined as an environmental purchasing initiative that aims to ensure purchased products and materials meet with environmental objectives set by the purchasing firm such as reducing sources of waste, encouraging recycling, and the reuse and substitution of materials (Huang, 2013; Carter and Ellram, 1998; Min and Galle, 2001). However, this has not always been the case as long as the performance of the packaged product constituted the single most important competitiveness factor on the market, the green packaging design of goods represented the most effective means of increasing competitiveness for a company (Marsh and Bugusu, 2007). There are knowledge gaps in our understanding of how the retailers may be related to the labelling management for food safety. Findings indicate possible associations between labelling, logos, and government guidelines like VietGAP in the retail food market. It remains an unsettled question whether there are consumer behaviour differences in perception and awareness of green food that is organically produced. Strong evidence is emerging that consumers are increasingly basing their purchasing 
behaviour on ethical and environmental criteria.

The effectiveness of labels is not clear in cases of the consumer who is not aware of sustainability issues and may not understand the information displayed on the label. Also, people face difficulties in recognizing eco-labels and distinguishing them from a regular one (Joshi and Rahman, 2015). The guideline of government policy and retailers responsible for food safety in Vietnam should develop a better-coordinated system for food safety labelling management. For example, green marketing as a better-coordinated system involves cleaner production and green packaging which are stringent food safety standards for farming and supply chain processing. In addition, the Vietnam Ministry of Agriculture and Rural Development explicitly aims to implement and reduce food safety incidents through a combination of legislation (Law on Food Safety (LoFS), No.55/QH12/2010) and retail modernization (Sperling, 2010).

The relationships between Green Supply Chain Management (GSCM) practices and Vietnamese consumer behaviour familiar with organic food consumption will be addressed in future studies because at present there are too few studies on food safety in the Asia-Pacific region, but in Vietnam particularly, literature on green packaging management research is rare. Despite the Aeon Citimart labels, Big C labels, and Giant labels consist of the VietGAP standards and the logo of VinEco that in a not effort to implement in improving the quality of products, of food safety management by applying the international standard strictly implements standards, hygiene on food safety, and brand logos in Kim and McDonald food safety labelling model. Aeon Citimart labels, Big C labels, and Giant labels consist of government standards only. The VietGAP labelling targets the consumers who perceived the adoption of this food safety standard to minimize or eliminate their exposure to biological, chemical, or any physical hazards related to the products purchased at each of the five retailers in Vietnam. In two retailers such as Aeon Citimart and Giant, successful approaches in terms of labelling and guidelines of government policy in the Vietnamese retail food market, VietGAP was incorporated into the value chain of their supply chain management, with an emphasis on labelling with the guideline of VietGAP and own logos of the retailer. However, the retailer of Giant needs to develop own brand logo for the food safety builds trust for their customer.

The present study showed that Vietnamese Good Agricultural Practices (VietGAP) standardization is certified by Vietnamese government policies and used by the private retail food sector in line with practices for labelling and logos on food safety labelling management. Furthermore, this study provides an insight into the importance of food safety labelling management in the retail food sector, and how it has been applied in Vietnam's retail food sector. Also, it has compared the green labelling and green packaging in Vietnam's retail food sector, and it was reviewed that there have been few empirical studies on green packaging management in Vietnam's retail food sector. Vietnam's government in the agriculture sector ensures that it can implement green packaging management practices that include a food safety standards system when sourcing food products to ensure that they only procure using the guidelines through VietGAP which provides standards and guidelines to assist individuals or organizations since 2008 . The focus on food safety needs to improve food safety labelling systems, own logos and guidelines of government policies for food safety and product quality by incorporating recyclability, and reuse waste resources in Green Supply Chain Management (GSCM) as well as focusing on environmental sustainability. In addition, Vietnam's food retail sector needs to improve the knowledge based on their research and development for food safety labelling management processing in the supply chain, in particular green labelling and guidelines of government policies.

Understanding the consumer behavior of a market is a crucial factor while an entrepreneur aims to achieve success in a new target market, so that academics and practitioners can take advantage of this research for other further studies. According to results from current research, the following suggestions were formed, in order to help retailers and manufacturers aim to meet the global standard and local standard on food safety for penetrating into Vietnam's retail food sector. The function of green packaging is required to maintain promoting production and quality of packaging. For example, the eco-friendly materials on ecological packaging materials directly related to protecting ability as well as maintaining the safety and stability of the supply chain. The competitive products with green benefits and food safety would be at an advantage in attracting consumers to choose the green products. Furthermore, knowledge about green labelling and guidelines of government policies should be raised among Vietnamese consumers for improving the consumer awareness of labelling and the packaging of products.

It is essential to continue developing a model of food safety management, with a focus on the guideline, logos, and labelling management and focus on food safety systems. The design of Kim and McDonald food safety labelling techniques suggest the effective collaboration between the guidelines of the government policy sector and the private sector in implementing the legal framework to ensure access to the retail food industry. The suggested Kim and McDonald food safety labelling techniques is to improve the quality of life both in Vietnam's retail food market and the global retail food market by improving their access to safe food and to minimize food risks due to pesticides, contamination or poor food safety management. To contribute to the improvement of food safety knowledge and living standards of the Vietnamese and global consumers by improving their access to easily check the labelling in terms of brand and eco symbol such as labelling, barcode, description of food safety system, and national legislation. The concept of Kim and McDonald food safety labelling techniques involves the regulation of inputs such as labelling and barcode, national legislation, HACCP and ISO, which implements logical conjunction. If all seven inputs of correct labelling contribute to the gate of food safety management, self-designed brands and Eco Symbols by retailers can be shown to have high output results in food safety labelling management.

Darnall, Jolley and Handfield, (2008) define Green Supply Chain Management (GSCM) as the application of 
environmental management principles to the entire set of activities across the whole customer order cycle, including design, procurement, manufacturing, assembly, packaging, logistics, and distribution. Another definition elaborates GSCM as a set of supply chain management policies and relationships that pay close consideration to the natural environment when an enterprise distributes its resources (Hervani, Helms and Sarkis, 2005; Zhu, Sarkis and Lai, 2008; Huang, 2013). In addition, Choong et al., (2010) stated that environmental awareness should be integrated into GSCM throughout the whole process, from international standards of raw materials to the terminal disposal of goods to achieve and minimize negative environmental effects to be sustainable.

Recently, Tundys and Rzeczycki, (2015) also claimed that Green Supply Chain Management (GSCM) is an increasingly expanded strategy by which to gain the most optimal performance for reducing the environmental costs of packaging. Khoi, Dung and Nga, (2016) conducted a study on Ajinomoto Japanese manufacturing and found that supply chain collaboration impacts a form of Research and Development (R\&D) investment in environmental technologies. The Ajinomoto Company applied $100 \%$ reusable waste during the plant operation. Furthermore, Negi (2016) conducted a study on the natural environment and is leading the agricultural industry by integrating environmental thinking into supply chain management. Three key areas such as green supply chain planning, green procurement, and green supply chain execution that implement GSCM have been proposed by Choong et al., (2010). According to Laarij, (2016), GSCM practices include the use of environmentally friendly materials and equipment, environmental policies and environmental audits. However, two key areas in GSCM practices were selected as the most significant those are related to the food safety labelling management which are environmentally friendly materials and environmental policies.

The advantage of Kim and McDonald food safety labelling techniques improve food safety labelling and environmental standards by using an observational study for improving the visualization of food safety labelling management and contributing an environmental solution in the following ways such as (1) To maximize the benefit of brand and Eco Symbol via access to food safety labelling management (2) To contribute to the improvement of labels and barcodes by adding the information to labels and barcodes such as the name of product, expiration and instructions for use (3) To contribute to the improvement of food safety by adding the information of national legislation such as GAP and quality control management (4) To strengthen GSCM practices and the manufacturing of raw materials for products in GSCM to ensure an effective implementation of its hazard and Critical Control Point as well as the description of the food safety systems.

The findings from the observational study imply that retailers prefer products with labelling with functional attributes (e.g. logos). The findings are implemented into Kim and McDonald food safety labelling techniques to improve the quality of life both in Vietnam's retail food market and the global retail food market by improving their access to safe food and to minimize food risks due to pesticides, contamination or poor food safety management. To contribute to the improvement of food safety knowledge and living standards of the Vietnamese and global consumers by improving their access to easily check the labelling in terms of brand and eco symbol such as labelling, barcode, description of food safety system, and national legislation.

In addition, suppliers, manufacturers, and retailers need to introduce innovative food products which combine green consumerism and functional attributes. In this research, the impact of demographic factors and consumer-related forces was not considered. Further research may examine green consumer buying behavior. Furthermore, research may investigate determinants of the relationships between the suggested Kim and McDonald food safety labelling techniques and consumer buying behavior towards food products in the retail food industry. The suggested Kim and McDonald food safety labelling techniques is to improve the quality of life both in Vietnam's retail food market and the global retail food market by improving their access to safe food and to minimize food risks due to pesticides, contamination or poor food safety management. To contribute to the improvement of food safety knowledge and living standards of the Vietnamese and global consumers by improving their access to easily check the labelling in terms of brand and eco symbol such as labelling, barcode, description of food safety system, and national legislation.

\section{Concluding remarks}

A contribution to practical perspective will support beneficial aspect to government policymakers, marketers, and consumers who can apply the practical perspective to their valuable food retail business sector. For example, consumerbased forces, market-based forces and consumer intention can use the information to improve food safety risks management in the retail food industry and promoting organic food consumption. The second contribution to practical perspective will be that it not only predicted food risks management, and organic products marketing but also consumer intention for organic food in Vietnamese food retail industry. This study can offer valuable information on the Vietnamese consumerism on organic food that can be used by the government policymakers and marketers in terms of the food safety policy level. For instance, with increasing green environment and food risks management, the Vietnamese government has become interested in policy on the Vietnamese good agricultural practices (VietGAP) which included of fresh fruit and vegetables in terms of food safety risk management (Ministry of Agriculture \& Rural Development, 2008).

The limitations of the study are that food safety labelling management in terms of labels promoting the organic food products indicate not only to the labelling ingredients and expiry date, and basic information but also represents the 
labelling techniques of organic food products such as national legislation, food safety standards processing system (e.g. manufacturer). Furthermore, as an access point, food safety labelling techniques may influence consumer trust in either the organic standard, food safety standard processing in industry, or the competence of national regulatory processes (e.g. brand logos, USDA, EU organic logos, ISO and HACCP) in the retail food sector. Further empirical research for consumer buying behavior towards organic food products in the retail food sector is needed to enable a more comprehensive understanding of the role of food safety labelling techniques plays in influencing consumer trust towards organic food products. This research examines the implementation of food safety labelling management into the retail market sector as an observational study to understand how the packaging and labelling build trust for food security. Further, this research develops a conceptual framework of the role of food safety labelling may play in influencing consumer trust in food safety standards through labelling management.

\section{References}

Alves, E., Edwards, M., 2008. The case for green food labels, Sustanable Development Law \& Policy 9, 51-55.

Auler, D.P., Teixeira, R., Nardi, V., 2017. Food safety as a field in supply chain management studies: A systematic literature review, International Food and Agribusiness Management Review 20, 99-112.

Australian Government, 2018. Vietnam Food and Beverage: 2016 - 2018 Opportunities under the Asean-Australia-New Zealand Free Trade Agreement, Australian Trade and Investment Commission. Australia.

Bendeković, J., Naletina, D., Nola, I., 2015. Food Safety and Food Quality in the Supply Chain, < https://bib.irb.hr/datoteka/786708.TP _Bendekovic_Naletina_Nola.pdf>

Bloch, P.H., 1995. Seeking the ideal form: Product design and consumer response, Journal of Marketing 59, 16-29.

Boström, M., Klintman, M., 2008. Green Labels and Other Eco-Standards: A Definition, Eco-Standards, Product Labelling and Green Consumerism, Palagrave Macmillan, London, UK.

Carter, C.R., Ellram., L.M., 1998. Reverse logistics: A review of the literature and framework for future investigations, Journal of Business Logistics 19, 85-102.

Cartín-Rojas, A., 2013. Closing gaps: Integrating food safety management systems into the veterinary curriculum a tool to improve food quality and trade, Veterinary Research Forum: An International Quarterly Journal 4, 205-206.

Chen, X., 2015. Consumers' willingness to pay for organic and local food: An experimental study using structural equation modeling, Master Thesis, University of Delaware, Delaware, USA.

Chiu, J.Z., Hsieh, C.C., 2016. The impact of restaurants' green supply chain practices on firm performance, Sustainability 8, 1-14.

Choong, C.K., Chew, B.C., Rizal, M.S., 2003. Implementation of green supply chain management for production: a case study in Sony (Malaysia) Sdn. Bhd, Journal of Technology Management and Business 1, 1-19.

Curl, C.L., Beresford, S.A.A., Fenske, R.A., Fitzpatrick, A.L., Lu, C., Nettleton, J.A., Kaufman, J.D., 2015. Estimating pesticide exposure from dietary intake and organic food choices: The multi-ethnic study of atherosclerosis (MESA), Environmental Health Perspectives 123, 475-483.

Darnall, N., Jolley, G.J., Handfield, R., 2008. Environmental management systems and green supply chain management: Complements for sustainability?, Business Strategy and the Environment 17, 30-45.

Deloitte Southeat Aisa, 2014. Retail in Vietnam: Emerging Market, Emerging Growth, < https://www2.deloitte.com/content/dam/Deloi tte/ie/Documents/ConsumerBusiness/2014-deloitte-ireland-retail-vietnam.pdf>

De Fazio, M., 2016. Agriculture and Sustainability of the welfare: The role of the short supply chain. Agriculture and Agricultural Science Procedia 8, 461-466.

Dries, M.A., 2017. Vietnam GVN Revised Decree on Goods Labeling, USDA Foreign Agricultural Service.

Frederick, H., Elting, J., 2013. Determinants of green supply chain implementation in the food and beverage sector, International Journal of Business Innovation and Research 7, 164-184.

Gadd, D., Karstedt, S., Messner, S.F., 2012. The SAGE Handbook of Criminological Research Methods, Sage, London, UK.

Giang, T.T.H., 2015. Environment friendly agriculture and organic agriculture in Vietnam, < https://www.naro.affrc.go.jp/archive/niae s/marco/marco2015/en/ws2-6_h_t_t_giang.pdf>

Hervani, A.A., Helms, M.M., Sarkis, J., 2005. Performance measurement for green supply chain management, Benchmarking: An International Journal 12, 330-353.

Huang, X., 2013. Green Supply Chain Management in Manufacturing Small and Medium-Sized Enterprises: Perspective from Chang Chiang Delta, Ph.D. Thesis, University of Liverpool, Liverpool, UK.

International Trade Centre, 2012. Packaging for Organic Foods. < http://www.intracen.org/Packaging-for-organic-foods-for-web>

Janssen, M., Hamm, U., 2014. Governmental and private certification labels for organic food: Consumer attitudes and preferences in Germany, Food Policy 49, 437-448.

Johansson, G., 2002. Success factors for integration of ecodesign in product development: A review of state of the art, Environmental Management and Health 13, 98-107.

Joshi, Y., Rahman, Z., 2015. Factors affecting green purchase behaviour and future research directions. Internaional Strategic Management Review 3, 128-143.

Junior, S.S.B., Silva, D., Gabriel, M.L.D.S., Braga, W.R.O., 2015. The effects of environmental concern on purchase of green products in retail, Procedia - Social and Behavioral Sciences 170, 99-108.

Keirin Association. 2006. Study on Strengthening Food Standards and The Certification System in the Socialist Republic of Vietnam Study Report. Engineering and Consulting Firms Association.

Khoi, N.V., Vu, A.D., Nguyen Q.N., 2016. R\&D investment of Japanese multinational corporations in Vietnam through green supply chain: The case of Ajinomoto, Journal of Sustainability Science and Management 11, 43-52. 
Kim, E.S., McDonald, S., 2018. Development of the food safety labelling technique for applied business in the Vietnamese retail food industry, Innovare Journal of Food Science 6, 1-7.

Laarij, S., 2016. Green Supply Chain Management Practices and Firm Performance: Evidence from Finland; Painosalama Oy: Turku, Finland.

Lakshmimeera, B.L., Chitramani Palanisamy, 2013. A conceptual framework on green supply chain management practices, Industrial Engineering Letters ISSN 2224-6096 (Paper) ISSN 2225-0581 (Online) 3, 42-52.

León-Bravo, V., Caniato, F., Caridi, M., Johnsen, T., 2017. Collaboration for sustainability in the food supply chain: A multi-stage study in Italy, Sustainability 9, 1253.

Marsh, K., Bugusu, B., 2007. Food Packaging - roles, materials, and environmental issues: Scientific status summary, Journal of Food Science 72, R38-R55

Mie, A., Andersen, H.R., Gunnarsson, S., Kahl, J., Kesse-Guyot, E., Rembiakowska, E., Quaglio, G., Grandjean, P., 2017. Human health implications of organic food and organic agriculture: A comprehensive review, Environmental Health 16, 1-23.

Min, H. Galle, W.P., 2001. Green purchasing practices of us firms, International Journal of Operations \& Production Management 21, 1222-1238.

Mohanty, R.P., Prakash, A., 2014. Green supply chain management practices in India: A confirmatory empirical study, Production \& Manufacturing Research: An Open Access Journal 2, 438-56.

Moisan, F., Spinosi, J., Delabre, L., Gourlet, V., Mazurie, J.L., Bénatru, I., Goldberg, M., Weisskopf, M.G., Imbernon, E., Tzourio, C., Elbaz. A., 2015. Association of parkinson's disease and its subtypes with agricultural pesticide exposures in men: A case-control study in France, Environmental Health Perspectives 123, 1123-1129.

National Assembly Standing Committee, 2003. Ordinance on food hygiene and safety, Socialist Republc of Vietnam.

Negi, S., Anand. N., 2016. Green and sustainable supply chain management practices - A study of Wal-mart, Emerging Business Sustainability, 141-157.

Nhung, T.T., Pensupar, K., 2015. Factors affecting consumers' decision to purchase VietGAP vegetables in Hanoi, Vietnam, Academic Fora 24, 54-64.

Niggli. U, Andres, C., Willer, H., Baker, B.P., 2017. A Global Vision and Strategy for Organic Farming Research, IFOAM.

Ntzani, E.E., Chondrogiorgi, M., Ntritsos G, Evangelou, E., Tzoulaki, I., 2013. Literature review on epidemiological studies linking exposure to pesticides and health effects. EFSA Supporting Publications 10, 1-157.

Olsson A., Lindh H., Bertoluci G., 2011. Packaging design in organic food supply chains -A case study in Sweden. 20th International Conference on Engineering Design ICED'11 Copenhagen, Denmark.

Pham, M., 2017. Factors affecting strategies for sustainable development of Viet Nam's retail supply chain, European Academic Reserch 5, 797-810.

Phung, D.T., Miller, G., Rutherford, S., Chu, C., 2012. Pesticide regulations and farm worker safety: The needs for improving pesticide regulations in Vietnam, Bull World Health Organ 90, 468-473

Qing, G., Guirong Z., 2012. The green packaging management for the logistics enterprises, Proceeding of 2012 International Conference on Information Management, Innovation Management and Industrial Engineering, ICIII 2012 1, 134-137.

Quang, L.L.E., 2014. Cultivation and marketing of organic rice in Vietnam - An economic analysis, Ph.D. Thesis, University of Agricultural Sciences, Bangalore, India.

Simmons, L.V., 2008. Moving towards agroecosystem sustainability: Safe vegetable production in Vietnam, Master Thesis, University of Waterloo, Waterloo, Canada.

Smith, G., Vo, K., 2016. Vietnam Retail Foods Sector Report 2016, USDA Foreign Agricultural Service.

Sperling, D., 2010. Food law, ethics, and food safety regulation: roles, justifications, and expected limits, Journal of Agricultural and Environmental Ethics 23, 267-278.

Srivastava, S.K., 2007. Green supply - chain management: A state-of-the-art literature review, International Journal of Management Reviews 9, 53-80.

Stolz, H., Stolze, M., Janssen, M., Hamm, U., 2011. Preferences and determinants for organic, conventional and conventional-plus products - the case of occasional organic consumers, Food Quality and Preference 22, 772-779.

Suansawat, R., 2013. The influence of supply chain integration and green supply chain management practices on sustainable firm performance - In thai manufacturing industry, Ph.D. Thesis, University of Hull, Hull, UK

Sulistio, J., Rini, T.A., 2015. A structural literature review on models and methods analysis of green supply chain management, Procedia Manufacturing 4, 291-299.

Szeremeta, A., Ball, K., Blake, F., Schlüter, M., Tuszynski, L., 2012. European Organic Regulations (EC) No 834/2007, 889/2008 and 1235/2008 - An Evaluation of the First Three Years Looking for Further Development, IFOAM EU Group.

Thuy, P.T., van Geluwe, S., Nguyen, V.A., van der Bruggen. B., 2012. Current pesticide practices and environmental issues in Vietnam: management challenges for sustainable use of pesticides for tropical crops in (South-East) Asia to avoid environmental pollution, Journal of Material Cycles and Waste Management 14, 379-387.

Tundys, B., Andrzej. R., 2015. Construction of green supply chain for organic products, Operations and Supply Chain Management 8. 37-47.

Van Maele-Fabry, G., Hoet, P., Lison, D., 2013. Parental occupational exposure to pesticides as risk factor for brain tumors in children and young adults: A systematic review and meta-analysis. Environment International 56, 19-31.

Vieira, L.M., De Barcellos, M.D., Hoppe, A., da Silva, S.B., 2013. An analysis of value in an organic food supply chain, British Food Journal 115, 1454-1472.

Vietnam Certification Centre. n.d., 2013. GOOD AGRICULTURE PRACTICE - VietGAP Standard, Available at http://www.quacert. gov.vn/en/good-agriculture-practice.nd185/vietgap-standard.i88.html (accesed March 12, 2018).

Vietnamnet, Bridge, 2018. Retailers Keen to Expand Supply of Organic Foods - News VietNamNet, Available at http://www.english.vi etnamnet.vn/fms/business/201230/retailers-keen-to-expand-supply-of-organic-foods.html (accesed July 2, 2018)

Wertheim-Heck, S.C.O., Vellema, S., Spaargaren, G., 2015. Food safety and urban food markets in Vietnam: The need for flexible and customized retail modernization policies, Food Policy 54, 95-106. 
World Bank, 2006. Vietnam: Food Safety and Agricultural Health Action Plan, World Bank Group.

World Bank, 2016. Vietnam Food Safety Risks Management, World Bank Group.

World Bank, 2017. Vietnam Food Safety Risks Management, World Bank Group

World Bank, 2016a. Transforming Vietnamese Agriculture: Gaining More from Less, World Bank Group.

World Bank, 2016b. Vietnam: Sustainable Farming Increases Productivity and Improves the Environment, World Bank Group.

Ye, M., Beach, J., Martin, J.W., Senthilselvan, A., 2015. Associations between dietary factors and urinary concentrations of organophosphate and pyrethroid metabolites in a Canadian general population, International Journal of Hygiene and Environmental Health 218, 616-626.

Young, J.G., Eskenazi, B., Gladstone, E.A., Bradman, A., Pedersen, L., Johnson, C., Barr, D.B., Furlong, C.E., Holland, N.T., 2005. Association between in utero organophosphate pesticide exposure and abnormal reflexes in neonates, Neuro Toxicology 26, 199209.

Zhao, B., Guo, Y., Wang, Y., Zhang, M., 2013. Research on the integrated system construction of green agriculture products supply chain based on the model differentiation, Journal of Communication and Information Science 3, 57-65.

Zhou, F.F., 2014. The theory of green packaging design and its application. Applied Mechanics and Materials 635-637, 248-252.

Zhu, Q., Sarkis, J., Lai, K., 2008. Confirmation of a measurement model for green supply chain management practices implementation, International Journal of Production Economics 111, 261-273. 